\title{
Clinical significance of sarcopenia in the treatment of patients with primary hepatic malignancies, a systematic review and meta-analysis
}

\author{
Guoqing Zhang ${ }^{1}$, Songfeng Meng ${ }^{1}$, Renfeng Li ${ }^{1}$, Jianwen $\mathrm{Ye}^{1}$ and Longshuan Zhao ${ }^{1}$ \\ ${ }^{1}$ Department of Hepatobiliary and Pancreatic Surgery, First Affiliated Hospital of Zhengzhou University, Zhengzhou, Henan \\ Province, China \\ Correspondence to: Longshuan Zhao, email: drzhangguoqing@163.com \\ Keywords: sarcopenia; hepatocellular carcinoma; intrahepatic cholangio-carcinoma; third lumbar skeletal muscle index; third \\ lumbar total psoas area \\ Received: February 25, $2017 \quad$ Accepted: June 05, 2017 Published: July 28, 2017 \\ Copyright: Zhang et al. This is an open-access article distributed under the terms of the Creative Commons Attribution License 3.0 \\ (CC BY 3.0), which permits unrestricted use, distribution, and reproduction in any medium, provided the original author and source \\ are credited.
}

\section{ABSTRACT}

Background: The impact of sarcopenia on outcomes following treatment for primary liver tumors remains contentious. Therefore, we performed a systematic literature review and meta-analysis to evaluate the clinical significance of sarcopenia in the treatment of patients with primary liver tumors.

Data sources: A systematic literature search was performed in English through February 1, 2017 in databases.

Results: There were significant differences between patients with and without sarcopenia in overall 1- and 3-year survival (1 year: OR: 0.43; 95\% CI: 0.27-0.68; $P=0.0004$; 3 year: OR: 0.67; 95\% CI: 0.47-0.96; $P=0.03)$. However, overall 5-year survival showed no significant difference between the groups (OR: $0.61 ; 95 \% \mathrm{CI}$ : $0.35-1.07 ; P=0.08$ ). Patients with sarcopenia showed a significant $53 \%$ reduction in disease-free survival within 5 years (OR: 0.47 ; 95\% CI: $0.28-0.79 ; P=0.005$ ). Also, sarcopenia had a significantly negative impact on recurrence in patients with primary liver tumors (RR: 2.71; 95\% CI: 1.46-5.05; $P=0.002$ ). Regarding complications rate, we concluded that there was a statistically significant difference between two groups in overall complications rate (RR: 2.52; 95\% CI: 1.50-4.22; $P=0.0005$ ). However, the major complications rate showed no significant difference between the groups (RR: 1.19; 95\% CI: 0.65-2.20; $P=0.57$ ).

Conclusions: Sarcopenia seemed to have a negative effect on overall survival in patients with primary liver tumors in the early phase post-treatment, but further research is needed to investigate the prognostic impact on overall survival over the longer term. Moreover, sarcopenia could significantly increase the incidence rates of post-treatment recurrence and overall complications in patients with primary liver tumors.

\section{INTRODUCTION}

Sarcopenia, which is defined as the loss of muscle mass and function [1], is critically involved not only in aging but also in a variety of chronic diseases, such as tuberculosis infection, chronic obstructive pulmonary disease (COPD), diabetes mellitus (DM), advanced organ failure and other wasting conditions. In recent years, studies have shown that sarcopenia is prevalent in patients with certain cancers $[2,3]$, and evidence has revealed its prognostic significance in oncologic patients [4-10]. A study by Chindaprasirt $\mathrm{J}$ [11] demonstrated that patients who suffered from sarcopenia had shorter median overall 
survival among cancer patients. More specifically, the frequency of sarcopenia varied greatly from $11.1 \%$ to $76 \%$ in patients with primary liver tumors (hepatocellular carcinoma (HCC) and intrahepatic cholangio-carcinoma (ICC)) [12-14], and the demonstration of the prognostic significance of sarcopenia has been reported relatively frequently in patients with primary liver tumors. To the best of our knowledge, several reviews [15-17] have shown that sarcopenia can be associated with impaired overall survival and increased postoperative morbidity in primary liver tumors. However, these studies have had several limitations. First, the reviews included studies evaluating different tumor types (including gastrointestinal and hepatopancreatobiliary malignancies). Second, the relationships between sarcopenia and the recurrence of malignancy or post-treatment complications (overall complications and major complications) were not described.

To date, it has been frustrating that there have been no systematic reviews specifically identifying sarcopenia in people with primary liver tumors, and the impact of sarcopenia on outcomes following treatment for primary liver tumors remains contentious. This systematic literature review and meta-analysis were performed to evaluate the clinical significance of sarcopenia in the treatment of patients with primary liver tumors. Outcomes of interest included overall survival, disease-free survival, recurrence of malignancy and post-treatment complications (overall complications and major complications).

\section{RESULTS}

\section{Literature selection}

Database searches yielded 71 entries, of which 52 were excluded because of duplications (29 trials) or irrelevance ( 23 trials). Of the 19 publications that qualified for abstract review, 1 was excluded because it was not a comparative trial, 1 trial was excluded because it included other malignancies than primary liver tumors, 4 trials were excluded because sarcopenia was not evaluated by the L3 skeletal muscle index (L3 SMI) or L3 total psoas area (L3 TPA), 2 trials were excluded because necessary data were not available, 2 trials were excluded because medical treatment was evaluated, and 1 trial was excluded because it was about postoperative sarcopenia. The Preferred Reporting Items for Systematic Reviews and MetaAnalysis (PRISMA) flow diagram for study selection is shown in Figure 1.

\section{Included trials and quality assessment}

Detailed characteristics of the included patients are listed in Table 1 . Of these 8 comparative trials, the Newcastle-Ottawa Scale (NOS) [18] was applied to determine the risk of bias in this literature. According to the scores (Table 2), all the included trials were considered high-quality (score $\geq 7$ ) trials.

\section{Overall survival (OS)}

Overall 1-, 3-, and 5-year survival was evaluated in our meta-analysis. Data on overall 1-year survival were available in 5 trials [12, 19, 21-23] including 582 participants, overall 3 -year survival was available in 5 trials $[12,19,21-23]$ including 582 participants, and overall 5-year survival was available in 5 trials [4, 12, 21, $23,24]$ including 823 participants. In our meta-analysis, we concluded that there were significant differences between patients with and without sarcopenia in overall 1and 3-year survival (1 year: OR: 0.43; 95\% CI: 0.27-0.68; $P=0.0004$; 3 year: OR: $0.67 ; 95 \%$ CI: $0.47-0.96 ; P=0.03$; Figure 2) with insignificant heterogeneity ( 1 year: $\chi^{2}=9.31$, $P=0.05, I^{2}=57 \%$; 3 year: $\chi^{2}=6.92, P=0.14, I^{2}=42 \%$; Figure $2)$. In contrast, patients with sarcopenia showed an insignificant 39\% reduction in OS within 5 years (OR: 0.61; 95\% CI: 0.35-1.07; $P=0.08$; Figure 2). A random effects model was used because of statistically significant heterogeneity ( $\chi^{2}=12.55, P=0.01, I^{2}=68 \%$; Figure 2 ).

\section{Disease-free survival (DFS)}

Overall 1-, 3-, and 5-year DFS was evaluated in our meta-analysis. Two trials [19, 22] including 199 participants reported data on 1-year DFS, two trials [19, 22] including 199 participants reported data on 3-year DFS, and three trials $[4,21,22]$ including 391 participants reported data on 5-year DFS. Our meta-analysis revealed that 1- and 3-year DFS showed no significant differences between patients with and without sarcopenia (1 year: OR: $0.81 ; 95 \%$ CI: $0.46-1.43 ; P=0.47 ; 3$ year: OR: $0.75 ; 95 \%$ CI: $0.36-1.55 ; P=0.44$; Figure 3 ). In contrast, patients with sarcopenia showed a significant $53 \%$ reduction in DFS within 5 years (OR: $0.47 ; 95 \%$ CI: $0.28-0.79 ; P=0.005$; Figure 3$)$. The results were homogeneous ( 1 year: $\chi^{2}=0.25$, $P=0.62, I^{2}=0 \%$; 3 year: $\chi^{2}=0.39, P=0.53, I^{2}=0 \% ; 5$ year: $\chi^{2}=3.64, P=0.16, I^{2}=45 \%$; Figure 3 ).

\section{Recurrence rate}

Two trials [12, 22] including 201 participants reported the recurrence of HCC/ICC after treatment. Our results showed that sarcopenia had a significantly negative impact on patients with $\mathrm{HCC} / \mathrm{ICC}$ (RR: 2.71; 95\% CI: 1.46-5.05; $P=0.002$; Figure 4). The results were homogeneous $\left(\chi^{2}=1.63, P=0.20, I^{2}=39 \%\right.$; Figure 4$)$.

\section{Post-treatment complication rate}

Complications were evaluated according to the Clavien-Dindo classification, and major complications (MCs) were defined as a Clavien-Dindo grade greater 
than 3. In our study, the impact of sarcopenia on overall complications (OCs) and major complications was examined.

Data on OCs were available in 3 trials [19, 21, 22], including 158 participants who were diagnosed with sarcopenia and 137 participants who were had normal L3 SMI/TPA. In our meta-analysis, we concluded that there were statistically significant differences between the two groups in OC rate (RR: $2.52 ; 95 \%$ CI: $1.50-4.22$; $P=0.0005$; Figure 5). The results were homogeneous $\left(\chi^{2}=1.44, P=0.49, I^{2}=0 \%\right.$; Figure 5).

Data on MCs were available in 7 trials [4, 19, 21-25] among the total of 497 participants who were diagnosed with sarcopenia and 572 participants with normal L3 SMI/ TPA. In our meta-analysis, we concluded that there was no statistically significant difference between the two groups in MC rate (RR: 1.19 ; 95\% CI: 0.65-2.20; $P=0.57$;
Figure 5). A random effects model was used because of statistically significant heterogeneity $\left(\chi^{2}=18.90, P=0.004\right.$, $I^{2}=68 \%$; Figure 5).

\section{DISCUSSION}

Numerous studies have demonstrated that there are correlations between sarcopenia and patients' basic characteristics, such as age [20-22, 24, 26, 27], sex [4, $12,23,27]$, liver function(serum albumin levels) [4, $22,23]$, and BMI values [4, 12, 19, 22-24, 26-28]. As reported, sarcopenia occurs during aging, and in patients with primary hepatic malignancies, this is possibly due to cachexia-associated processes. Accordingly, in patients with primary hepatic malignancies, sarcopenia is prevalent across all ages but particularly in the elderly [20-22, 24, 26, 27]. Moreover, because of faster deterioration of
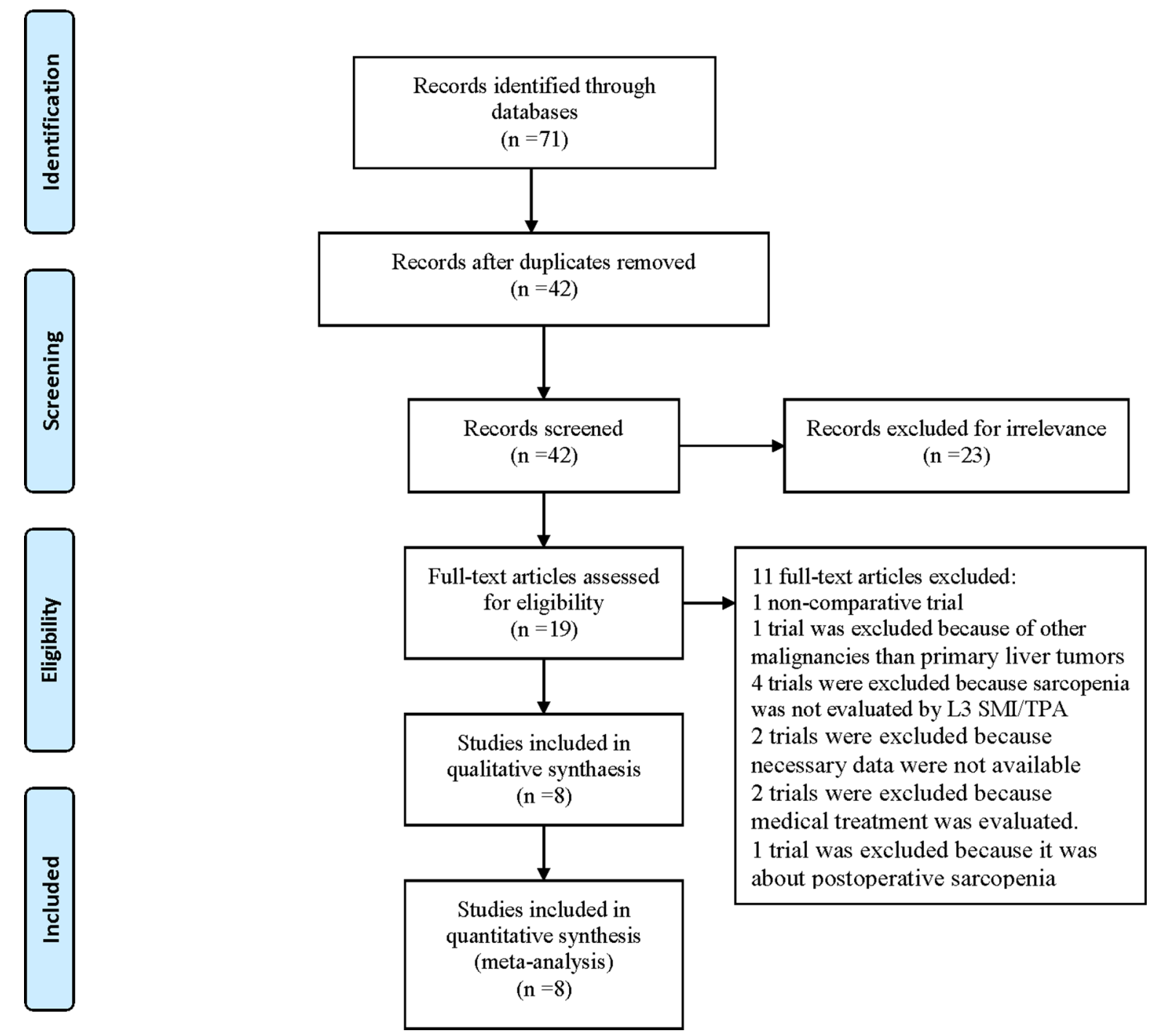

Figure 1. PRISMA 2009 Flow Diagram. 
Table 1: The characteristics of the included studies

\begin{tabular}{|c|c|c|c|c|c|c|c|c|}
\hline Study & country & Study design & $\begin{array}{c}\text { Group } \\
\text { assignment }\end{array}$ & $\begin{array}{c}\text { Histopathological } \\
\text { type }\end{array}$ & Treatment & CT scan & $\begin{array}{c}\text { significant } \\
\text { characteristics^ }\end{array}$ & $\begin{array}{c}\text { Definition of } \\
\text { sarcopenia }\end{array}$ \\
\hline \multirow[t]{2}{*}{$\begin{array}{l}\text { Harimoto } \\
\text { et al } 2013\end{array}$} & England & Retrospective & Sarcopenia & $\mathrm{HCC}$ & hepatectomy & $\begin{array}{l}\text { performed } \\
\text { preoperative }\end{array}$ & $\begin{array}{l}\text { Sex, BMI, } \\
\text { Albumin, } \\
\text { ICGR15 }\end{array}$ & $\begin{array}{c}\text { L3 SMI } \\
\leq 43.75 \mathrm{~cm} 2 / \\
\mathrm{m} 2 \text { for men } \\
\text { and } 41.10 \\
\mathrm{~cm} 2 / \mathrm{m} 2 \text { for } \\
\text { women; }\end{array}$ \\
\hline & & & No-sarcopenia & & & & & \\
\hline $\begin{array}{l}\text { Levolger } \\
\text { et al } 2015\end{array}$ & USA & Retrospective & Sarcopenia & $\mathrm{HCC}$ & $\begin{array}{l}\text { Hepatectomy } \\
\text { or RFA }\end{array}$ & $\begin{array}{c}\text { performed } \\
<3 \text { months } \\
\text { prior to or } \\
3 \text { days after } \\
\text { treatment }\end{array}$ & BMI & $\begin{array}{c}\text { L3 } \mathrm{SMI} \leq 52.0 \\
\mathrm{~cm} 2 / \mathrm{m} 2 \text { for } \\
\text { men and } \leq \\
39.5 \mathrm{~cm} 2 / \mathrm{m} 2 \\
\text { for women; }\end{array}$ \\
\hline \multirow[t]{2}{*}{$\begin{array}{l}\text { Valero et } \\
\text { al } 2015\end{array}$} & USA & Retrospective & No-sarcopenia & $\mathrm{HCC}$ or ICC & $\begin{array}{l}\text { Resection } \\
\text { or LT }\end{array}$ & $\begin{array}{c}\text { performed } \\
<60 \text { days } \\
\text { prior to or } \\
10 \text { days after } \\
\text { treatment }\end{array}$ & NR & $\begin{array}{c}\text { L3 TPA } \\
\leq 784.0 \mathrm{~mm} 2 / \\
\mathrm{m} 2 \text { for men } \\
\text { and } \leq 642.1 \\
\mathrm{~mm} 2 / \mathrm{m} 2 \text { for } \\
\text { women; }\end{array}$ \\
\hline & & & No-sarcopenia & & & & & \\
\hline $\begin{array}{l}\text { Voron et } \\
\text { al } 2015\end{array}$ & USA & Retrospective & Sarcopenia & $\mathrm{HCC}$ & Hepatectomy & $\begin{array}{c}\text { performed } \\
<2 \text { months } \\
\text { prior to or } \\
7 \text { days after } \\
\text { treatment }\end{array}$ & $\begin{array}{l}\text { Age, Stature, } \\
\text { BMI, Albumin }\end{array}$ & $\begin{array}{l}\text { L3 SMI } \\
\leq 52.4 \mathrm{~cm} 2 / \\
\mathrm{m} 2 \text { for men } \\
\text { and } \leq 38.9 \\
\mathrm{~cm} 2 / \mathrm{m} 2 \text { for } \\
\text { women; }\end{array}$ \\
\hline
\end{tabular}

No-sarcopenia

Harimoto et al 2016

Netherlan ds Retrospective Sarcopenia

$\mathrm{HCC}$

Hepatectomy

performed
preoperative

the actual L3

SMI was $85 \%$

HBV, HCV, smaller than

Skeletal muscle the calculated

mass skeletal

muscle

area\&;

No-sarcopenia

Kamachi
et al 2016 Netherlan ds Retrospective Sarcopenia

HCC

Hepatectomy performed or RFA preoperative

Sex, BMI, DM,

L3 SMI $\leq 52.4$ $\mathrm{cm} 2 / \mathrm{m} 2$ for

No-sarcopenia

Yabusaki

et al 2016

England Retrospective Sarcopenia

HCC

performed preoperative

Sex, BMI, Albumin, Number of

L3 SMI $\leq 43.75 \mathrm{~cm} 2$ $\mathrm{m} 2$ for men and 41.10 $\mathrm{cm} 2 / \mathrm{m} 2$ for women;

No-sarcopenia

Takagi et al 2016

Japan

Retrospective

Sarcopenia

HCC

performed

$<3$ months

prior to

treatment

L3 SMI $\leq 46.4$

Age, BMI, MVI, Tumor stage $\mathrm{cm} 2 / \mathrm{m} 2$ for men and 37.6 $\mathrm{cm} 2 / \mathrm{m} 2$ for women;

No-sarcopenia

(Condinued) 


\begin{tabular}{|c|c|c|c|c|c|c|c|c|c|c|c|c|c|}
\hline Study & $\begin{array}{c}\text { Group } \\
\text { assignment }\end{array}$ & patients(M/F) & $\operatorname{Age}(y)^{*}$ & & OS & & & DFS & & Recurrence & OC & MC & Follow-up ${ }^{\dagger}$ \\
\hline & & & & 1 & 3 & 5 & 1 & 3 & 5 & & & & \\
\hline \multirow[t]{2}{*}{$\begin{array}{l}\text { Harimoto } \\
\text { et al } 2013\end{array}$} & Sarcopenia & $75(50 / 25)$ & 67 & NR & NR & 53 & NR & NR & 10 & NR & 24 & NR & Every month ${ }^{\#}$ \\
\hline & No-sarcopenia & $111(95 / 16)$ & 66 & NR & NR & 93 & NR & NR & 37 & NR & 56 & NR & \\
\hline \multirow[t]{2}{*}{$\begin{array}{l}\text { Levolger } \\
\text { et al } 2015\end{array}$} & Sarcopenia & $52(39 / 13)$ & $61(22-86)$ & 37 & 16 & NR & 24 & 8 & NR & NR & 24 & 17 & $>60$ \\
\hline & No-sarcopenia & $38(24 / 14)$ & $62(25-77)$ & 35 & 22 & NR & 21 & 9 & NR & NR & 13 & 5 & \\
\hline \multirow[t]{2}{*}{$\begin{array}{l}\text { Valero et } \\
\text { al } 2015\end{array}$} & Sarcopenia & 47 & NR & 36 & 29 & 26 & NR & NR & 18 & NR & 19 & 11 & $>24$ \\
\hline & No-sarcopenia & 49 & NR & 43 & 35 & 34 & NR & NR & 25 & NR & 9 & 0 & \\
\hline \multirow[t]{2}{*}{$\begin{array}{l}\text { Voron et } \\
\text { al } 2015\end{array}$} & Sarcopenia & $59(53 / 6)$ & $64.55 \pm 12.92$ & 41 & 10 & NR & 26 & 10 & 3 & 42 & 23 & 13 & 21.2 \\
\hline & No-sarcopenia & $50(39 / 11)$ & $58.25 \pm 13.08$ & 48 & 11 & NR & 23 & 9 & 1 & 20 & 18 & 8 & \\
\hline \multirow[t]{2}{*}{$\begin{array}{l}\text { Harimoto } \\
\text { et al } 2016\end{array}$} & Sarcopenia & $57(40 / 17)$ & $76.5 \pm 3.9$ & NR & NR & NR & NR & NR & NR & NR & 7 & NR & Every month ${ }^{\#}$ \\
\hline & No-sarcopenia & $82(58 / 24)$ & $75.9 \pm 4.0$ & NR & NR & NR & NR & NR & NR & NR & 15 & NR & \\
\hline \multirow[t]{2}{*}{$\begin{array}{l}\text { Kamachi } \\
\text { et al } 2016\end{array}$} & Sarcopenia & $61(51 / 10)$ & $73(49-84)$ & 56 & 45 & 31 & NR & NR & NR & 50 & NR & NR & $29.7(3.9-107.6)$ \\
\hline & No-sarcopenia & $31(14 / 17)$ & $70(47-80)$ & 30 & 28 & 21 & NR & NR & NR & 23 & NR & NR & \\
\hline \multirow[t]{2}{*}{$\begin{array}{l}\text { Yabusaki } \\
\text { et al } 2016\end{array}$} & Sarcopenia & $89(57 / 32)$ & $66.2 \pm 10.1$ & 71 & 48 & 28 & NR & NR & NR & NR & 18 & NR & $37.4(1.2-120.7)$ \\
\hline & No-sarcopenia & $106(100 / 6)$ & $63.8 \pm 10.1$ & 86 & 55 & 33 & NR & NR & NR & NR & 23 & NR & \\
\hline \multirow[t]{2}{*}{$\begin{array}{l}\text { Takagi et } \\
\text { al } 2016\end{array}$} & Sarcopenia & $118(93 / 25)$ & $68.6 \pm 10$ & NR & NR & 69 & NR & NR & NR & NR & NR & 19 & $41.8(1-109)$ \\
\hline & No-sarcopenia & $136(114 / 22)$ & $63.1 \pm 10.3$ & NR & NR & 112 & NR & NR & NR & NR & NR & 16 & \\
\hline
\end{tabular}

Abbreviations: BMI, body mass index; BSA, body surface area; DFS, disease-free survival; DM, diabetes mellitus; HCC, hepatocellular carcinoma; ICC, intrahepatic cholangio-carcinoma; LT, liver transplantation; MC, major complication; MVI, microvascular invasion; NOS, Newcastle-Ottawa Scale; NR, no report; OC, overall complication; OS, overall survival; PT, prothrombin time; RFA, radiofrequency ablation; TPA, total psoas area;

${ }^{*}$ Age (year) is given in mean (minimum $\sim$ maximum) or mean $\pm \mathrm{SD}$

${ }^{\wedge}$ Significant clinicopathological factors between patients with and without sarcopenia

†Time given in month

\#all patients were examined monthly for recurrence by ultrasonography and estimation of tumor markers (AFP, DCP) and by CT every 3-6 months.

\& The formulae to calculate skeletal muscle area:126.9 $\times$ BSA-66.2 for men and 125.6×BSA-81.1 for women;

muscle mass in men than in women, at older ages, men experience greater losses of muscle mass than women $[29,30]$; thus, with regard to sex differences, sarcopenia is more common in men than women $[4,12]$. However, a study by Yabusaki et al. [23] showed that the results for sex differences seemed to contradict the present findings. Furthermore, patients with sarcopenia have significantly lower BMI values than patients without sarcopenia, and the serum albumin levels of these patients are generally lower [4, 22, 23]. In limited studies, sarcopenia was correlated with number of tumors [23], micro-vascular invasion [24] and tumor stage [24], which would seem to contradict the present findings. We found no correlations between sarcopenia and tumor size, Child-Pugh grade, Model for End-stage Liver Disease (MELD) score, liver cirrhosis, Barcelona Clinic Liver Cancer (BCLC) classification or tumor differentiation. There have been no reports concerning the relationships between sarcopenia and lymph node metastasis, distant metastasis or positive surgical margin. Additionally, skeletal muscle protein breakdown occurs mainly because of age-related low-grade systemic inflammation, alongside physical 
Table 2: The Newcastle-Ottawa Scale for assessing the quality of included studies

\begin{tabular}{|c|c|c|c|c|c|c|c|c|c|}
\hline \multirow{2}{*}{$\begin{array}{l}\text { Included } \\
\text { studies }\end{array}$} & \multicolumn{4}{|c|}{ Selection } & \multicolumn{2}{|l|}{ Comparability } & \multicolumn{2}{|l|}{ Outcome } & \multirow{2}{*}{$\begin{array}{l}\text { Total } \\
\text { score }\end{array}$} \\
\hline & $\begin{array}{c}\text { Representativeness } \\
\text { of the exposed } \\
\text { cohort }\end{array}$ & $\begin{array}{c}\text { Selection } \\
\text { of the } \\
\text { non- } \\
\text { exposed } \\
\text { cohort }\end{array}$ & $\begin{array}{c}\text { Ascertainment } \\
\text { of exposure }\end{array}$ & $\begin{array}{l}\text { Demonstration } \\
\text { that outcome } \\
\text { of interest was } \\
\text { not present at } \\
\text { start of study }\end{array}$ & $\begin{array}{l}\text { Comparability } \\
\text { of cohorts on } \\
\text { the basis of } \\
\text { the design or } \\
\text { analysis }\end{array}$ & $\begin{array}{l}\text { Assessment } \\
\text { of outcome }\end{array}$ & $\begin{array}{l}\text { Was follow- } \\
\text { up long } \\
\text { enough for } \\
\text { outcomes to } \\
\text { occur }\end{array}$ & $\begin{array}{l}\text { Adequacy } \\
\text { of follow } \\
\text { up of } \\
\text { cohorts }\end{array}$ & \\
\hline $\begin{array}{l}\text { Total } \\
\text { score }\end{array}$ & 1 & 1 & 1 & 1 & 2 & 1 & 1 & 1 & 9 \\
\hline $\begin{array}{l}\text { Harimoto } \\
\text { et al } 2013\end{array}$ & 1 & 1 & 1 & 1 & 2 & 0 & 0 & 1 & 7 \\
\hline $\begin{array}{l}\text { Levolger } \\
\text { et al } 2015\end{array}$ & 1 & 1 & 1 & 1 & 2 & 1 & 1 & 1 & 9 \\
\hline $\begin{array}{l}\text { Valero et } \\
\text { al } 2015\end{array}$ & 1 & 1 & 1 & 1 & 2 & 1 & 0 & 1 & 8 \\
\hline $\begin{array}{l}\text { Voron et } \\
\text { al } 2015\end{array}$ & 1 & 1 & 1 & 1 & 2 & 1 & 1 & 1 & 9 \\
\hline $\begin{array}{l}\text { Harimoto } \\
\text { et al } 2016\end{array}$ & 1 & 1 & 1 & 1 & 2 & 1 & 0 & 1 & 8 \\
\hline $\begin{array}{l}\text { Kamachi } \\
\text { et al } 2016\end{array}$ & 1 & 1 & 1 & 1 & 2 & 1 & 0 & 1 & 8 \\
\hline $\begin{array}{l}\text { Yabusaki } \\
\text { et al } 2016\end{array}$ & 1 & 1 & 1 & 1 & 2 & 1 & 1 & 1 & 9 \\
\hline $\begin{array}{l}\text { Takagi et } \\
\text { al } 2016\end{array}$ & 1 & 1 & 1 & 1 & 2 & 1 & 1 & 1 & 9 \\
\hline
\end{tabular}

inactivity and malnutrition in the elderly. This low-grade systemic inflammation is characterized by elevated proinflammatory cytokines and is caused by age-related cell damage and mitochondrial dysfunction [3]. However, there have been no reports concerning the relationship between sarcopenia and white blood cell counts, neutrophil-tolymphocyte ratios (NLRs) or C-reaction protein (CRP).

Sarcopenia has been revealed to be an unfavorable prognostic factor for clinical outcomes in cancer. However, whether this finding also holds true in patients with primary hepatic malignancies has increasingly been explored recently. Unfortunately, this research field has been severely hampered by a lack of consensus on the definition of sarcopenia, and the definition of sarcopenia has varied even among studies conducted by researchers in the same country $[19,21,22]$. Consequently, the prevalence of sarcopenia has varied widely, from $11.1 \%$ to $76 \%$ across published studies. CT scanning is the gold standard tool to quantify skeletal muscle mass [31] and hence constitutes a good resource for objective identification of sarcopenia. To avoid intrinsic bias, we chose trials in which sarcopenia was defined using a L3 SMI/TPA cut-off rather than intramuscular adipose tissue content (IMAC) or visceral fat area (VFA) in our meta- analysis. However, the included studies' evaluations of different cut-off values for sarcopenia undoubtedly led to bias between the associations of sarcopenia with clinical outcomes.

In recent years, the clinical significance of sarcopenia has been reported relatively frequently in patients with primary hepatic malignancies, and concerns about the impact of sarcopenia on outcomes following treatment could not be confirmed in various studies. Levolger et al. [19] showed that sarcopenia was associated with impaired survival $(P=0.002)$ in patients with $\mathrm{HCC}$, and MCs were more frequent $(P=0.033)$ in sarcopenic patients. However, a study by Yabusaki et al. [23] showed that there was no significant correlation between $\operatorname{OS}(P=0.72)$, and there was no difference in the incidence of postoperative MCs $(P=0.62)$ between the two groups. The difference might have derived from the inclusion criteria because Levolger et al. included patients with hepatocellular carcinoma undergoing treatment with curative intent (hepatectomy or RFA), while Yabusaki et al. enrolled patients who underwent primary hepatectomy for hepatocellular carcinoma. Also, the relatively small number of participants could have biased the results. Our systematic review and meta-analysis confirmed that 
patients with sarcopenia had a statistically significantly poorer prognosis (overall 1- and 3-year survival, 5-year DFS, incidence of recurrence and post-treatment OCs) than those without sarcopenia. In contrast, there were no significant differences in overall 5-year survival, 1- and 3-year DFS or post-treatment MC.

Yabusaki et al. [23] reported that sarcopenia impairs OS, mainly due to an increase in treatmentrelated deaths $(P=0.029)$. Evidence has shown that sarcopenic patients with primary hepatic malignancies seem to be less able to recover from treatment. Although the mechanisms by which sarcopenia affects patients' recovery are not fully understood, differences in the severity of the underlying liver disorders impacting skeletal muscle mass might very well play a part.
Studies have shown that patients with sarcopenia are more susceptible to bacterial infection, slow wound healing and longer length of hospital stays [32, 33], which might explain why sarcopenia has an adverse impact on short-term overall survival, consistent with our study that patients with sarcopenia had poorer overall 1- and 3-year survival but better overall 5 -year survival. However, the available data from our meta-analysis suggested that sarcopenia increases the incidence of recurrence significantly with poor 5-year DFS. As reported, recurrence of HCC after curative treatment remains a major challenge for the management of liver malignancy, and recent studies have widely shown that sarcopenia was a strong and independent prognostic factor for recurrence after liver resection for

(a)

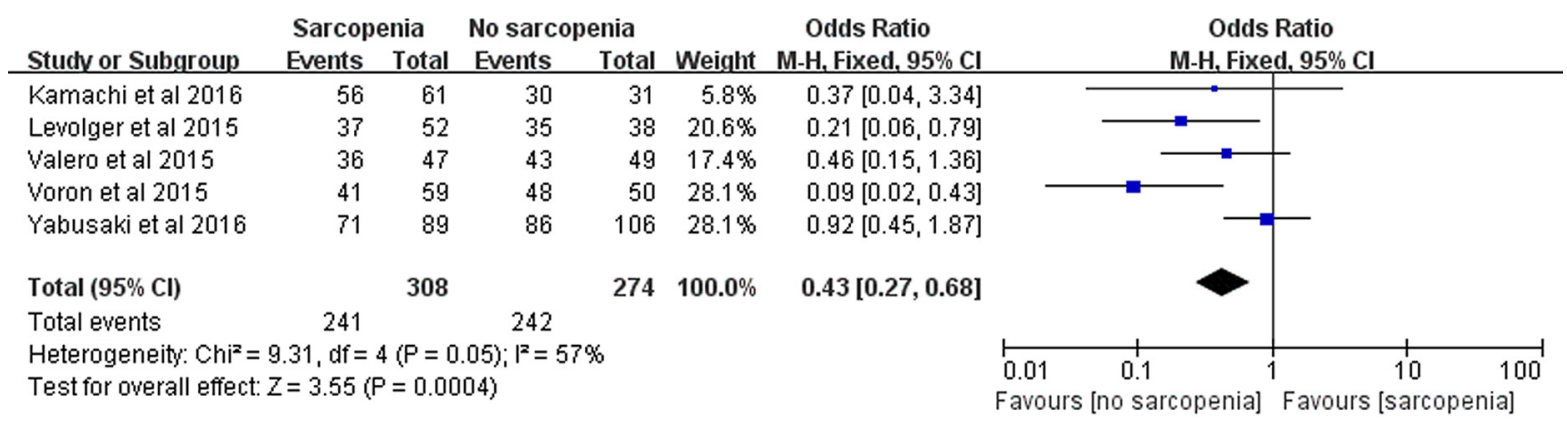

(b)

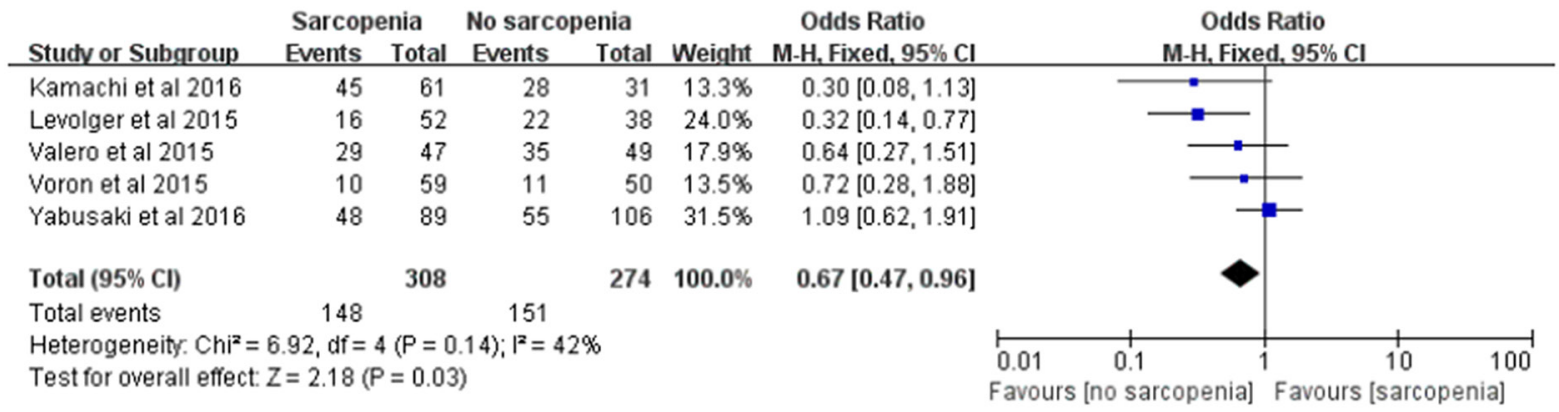

(c)

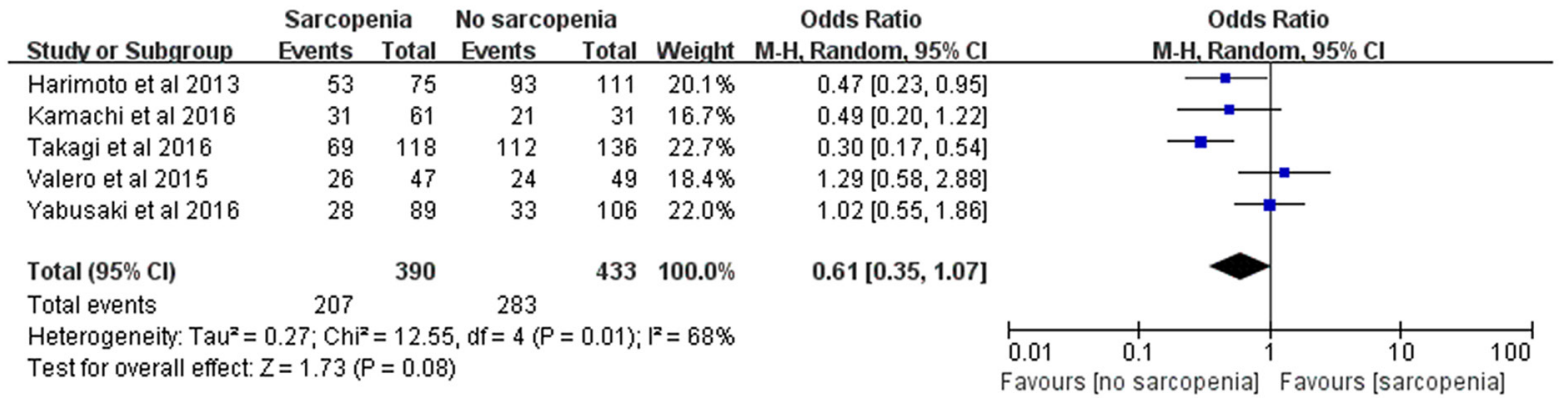

Figure 2. Meta-analysis of the overall 1-, 3- and 5-year survival. (a) Overall 1-year survival. (b) overall 3-year survival. (c) overall 5-year survival. 
HCC $[22,34]$, which was in agreement with our finding. Therefore, whether the reduction in OS found in patients with sarcopenia is due to increased recurrent malignancy or due to increased treatment-related mortality remains controversial. Combining the evidence revealed by Yabusaki et al. [23] that sarcopenia impairs OS mainly due to an increase in treatment-related deaths, we can conclude that sarcopenia impairs OS due to a combination of treatment-related deaths and recurrence of malignancy. That is, treatment-related death plays a primary role in the early phase (within 3 years) posttreatment, while recurrence plays a primary role over the longer term (perhaps more than 5 years) after treatment, which could explain our results that sarcopenia resulted in poorer 5-year DFS but better 1- and 3-year DFS. The reduction in OS (1- and 3-year) in patients with sarcopenia and lack of associations with DFS (1- and 3 -year) between groups also suggested that there are

(a)

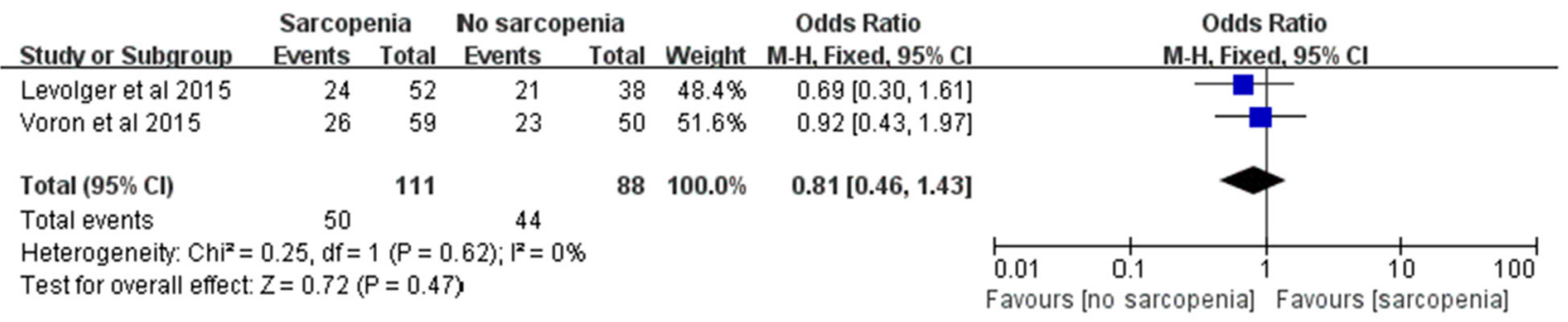

(b)

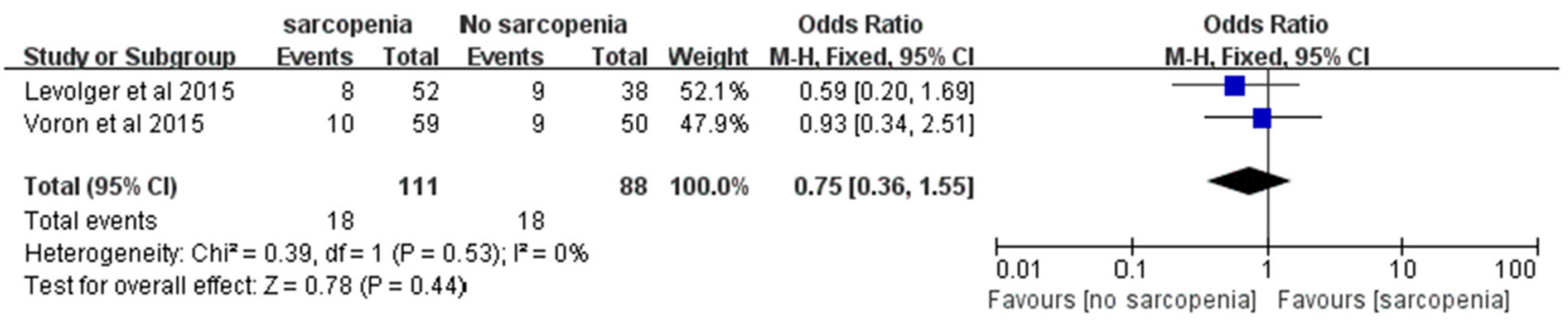

(c)

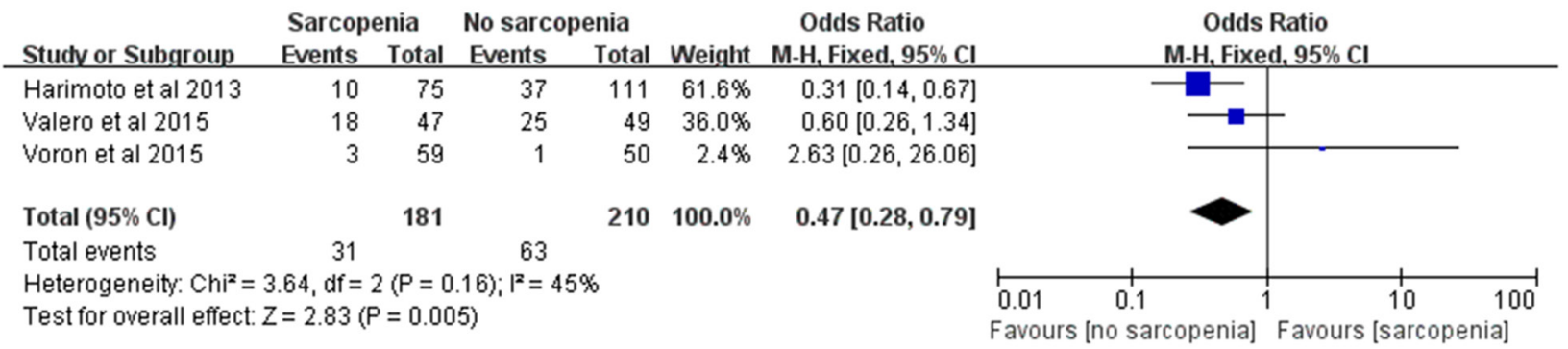

Figure 3. Meta-analysis of the 1-, 3- and 5-year disease-free survival. (a) 1-year disease-free survival. (b) 3-year disease-free survival. (c) 5-year disease-free survival.

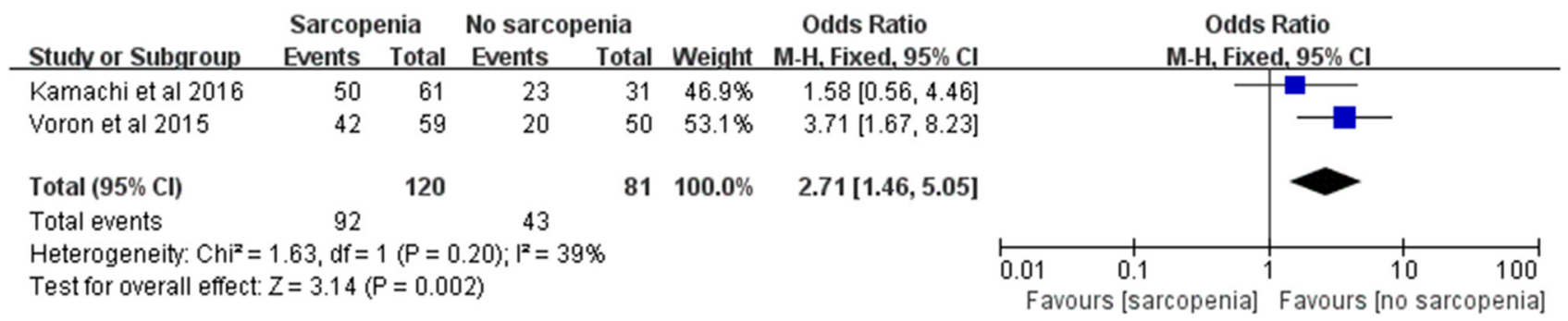

Figure 4. Meta-analysis of the recurrence rate. 
perhaps other factors associated with poor survival in patients with sarcopenia. As reported, sarcopenia can be merely a secondary finding of longstanding chronic disease such as diabetes, gastrointestinal disorders, and cardiovascular diseases. This finding is in agreement with our results that sarcopenia was not associated with DFS (1- and 3-year) between groups because non-liver- or non-HCC/ICC-related factors are also related to prognosis. Interestingly, we noted that patients with sarcopenia had poorer 5-year DFS but better overall 5-year survival. The reason for this inconsistency is undoubtedly multi-factorial. As in our previous descriptions, sarcopenia increases the incidence of recurrence significantly, so more patients die from recurrence of malignancy in patients with sarcopenia on the basis of similar OS to that of patients without sarcopenia, which results in poorer 5-year DFS in patients with sarcopenia. Also, the available data suggested that the number of patients/trials on DFS and recurrence might have been too small, so bias cannot be excluded.

Regarding post-treatment complications, they remain controversial. Valero et al. [21] showed that the presence of sarcopenia was an independent predictive factor of OCs and MCs. However, evidence [19] has also shown sarcopenia did not increase the incidence of OCs. The available data from our meta-analysis suggested that sarcopenia increased the incidence of OCs significantly. However, our study provided no evidence of an increased risk of MCs in sarcopenic patients. The reasons below might account for the nonstatistically significant difference in MCs: 1) patients with sarcopenia might receive more intensive care before, during and after treatment; and 2) the absence of a sub-analysis of each complication might have caused potential bias because each complication that develops after HCC/ICC treatment could have a different relationship or causality with sarcopenia and a different impact of prognosis.

Our present meta-analysis had several limitations. In particular, the absence of randomized, controlled clinical trials and the preponderance of retrospective studies could have biased the results to some extent. Second, the relatively small number of participants could have biased the results. Third, several trials were excluded because sarcopenia was not evaluated by L3 SMI/TPA, which could have caused potential bias. Fourth, no subgroup analysis could be conducted because the data extracted from the included studies were not disaggregated by groups. Fifth, the absence of a consistent duration between CT scans and treatment might have created potential bias. Sixth, we failed to elucidate whether sarcopenia was truly

(a)

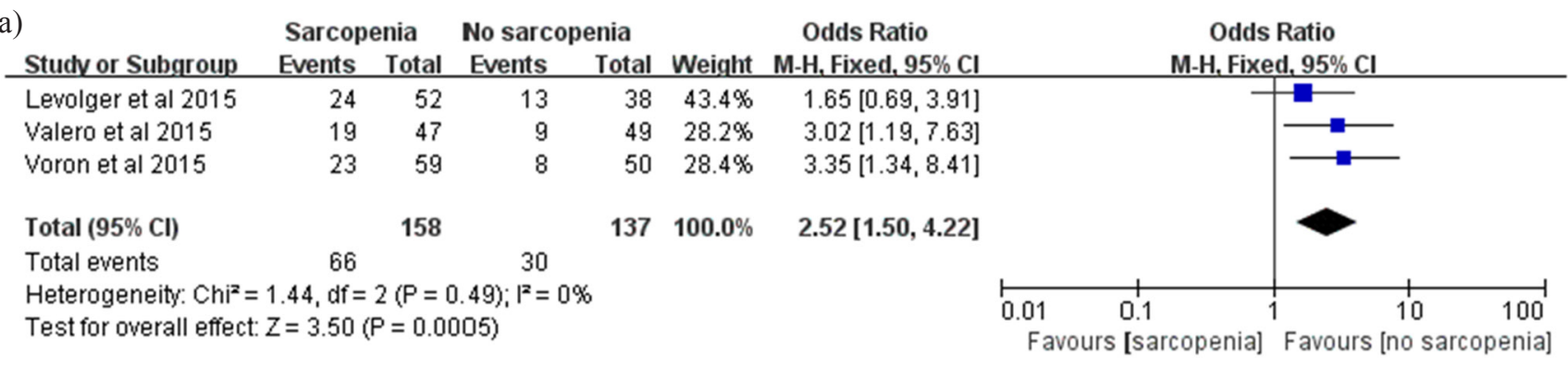

(b)

\begin{tabular}{|c|c|c|c|c|c|}
\hline \multirow[b]{2}{*}{ Study or Subgroup } & \multicolumn{2}{|l|}{ sarcop } & \multicolumn{2}{|r|}{ 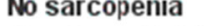 } & \multirow[b]{2}{*}{ Weight M } \\
\hline & Events & Iotal & Events & Total & \\
\hline Harimoto et al 2013 & 24 & 75 & 56 & 111 & $18.7 \%$ \\
\hline Harimoto et al 2016 & 7 & 57 & 15 & 82 & $14.6 \%$ \\
\hline Levolger et al 2015 & 17 & 52 & 5 & 38 & $13.1 \%$ \\
\hline Takagi et al 2016 & 19 & 118 & 16 & 136 & $17.5 \%$ \\
\hline Yalero el al 2015 & 11 & 47 & 0 & 49 & $3.8 \%$ \\
\hline Yoron et al 2015 & 13 & 59 & 8 & 50 & $14.5 \%$ \\
\hline Yabusaki et al 2016 & 18 & 89 & 23 & 106 & $17.7 \%$ \\
\hline Total $(95 \% \mathrm{Cl})$ & & 497 & & 572 & $100.0 \%$ \\
\hline Total events & 109 & & 123 & & \\
\hline
\end{tabular}

Odds Ratio Odds Ratio M-H, Random, $95 \% \mathrm{Cl}$ \begin{tabular}{rl|l|}
$0.46[0.25,0.85]$ & \\
$0.63[0.24,1.65]$ \\
$3.21[1.06,9.68]$ \\
$1.44[0.70,2.95]$ \\
$1.19[1.78,546.58]$ \\
$1.48[0.56,3.93]$ \\
$0.91[0.46,1.83]$ \\
$1.19[0.65,2.20]$
\end{tabular}

Figure 5. Meta-analysis of the post-treatment complication rate. (a) Overall complication. (b) major complication. 
a causal factor of poor prognosis or merely a concomitant finding of primary hepatic malignancies or a type of comorbidity.

\section{MATERIALS AND METHODS}

\section{Search strategy and study selection}

This systematic literature review and meta-analysis were performed using the methodology suggested by the PRISMA guidelines. A systematic literature search was performed in English through February 1, 2017, in the following databases: Medline, PubMed, Medline, Embase, Web of Science and the Cochrane Library. The key words used were "sarcopenia," "hepatocellular carcinoma," "intrahepatic cholangio-carcinoma," "primary hepatic malignancy," "third lumbar skeletal muscle index," "third lumbar total psoas area," and abbreviations thereof. The key words were combined with appropriate Boolean operators, and for further relevant articles, we also checked the reference lists of all the identified trials. After completing the literature searches, titles and abstracts of the studies were screened by two authors, and any disagreement was resolved by discussion or, if necessary, adjudicated by a third author.

\section{Inclusion and exclusion criteria}

The inclusion criteria were as follows: 1) a prospective or retrospective cohort study was adopted; 2) the L3 SMI/TPA was measured by CT scan; and 3) patients were examined regularly and had a minimum follow-up duration of 12 months. When the same patient cohort overlapped among different publications, only the latest or complete study was considered.

The following studies were considered to be ineligible: 1) studies associated with animals; 2) case reports or studies in which the control groups were not well designed; 3) post-treatment sarcopenia; 4) and sarcopenia evaluated by intramuscular adipose tissue content (IMAC)/visceral fat area (VFA) rather than by L3 SMI/TPA.

\section{Data extraction and study quality}

Data extraction was performed independently by two authors using a standard form. The following data were extracted from each study: the basic information of the study (surname of the first author and year of publication, country of the procedure performed, study design, group assignment, histopathological type, treatment, CT scan parameters, definition of sarcopenia, number of patients and ages, follow-up duration) and the clinical significance of sarcopenia in the treatment of HCC/ICC (overall survival, disease-free survival, recurrence of malignancy, overall complications and major complications). The methodological quality of each trial was assessed according to the NOS, which evaluates included studies based on three broad perspectives: 1) selection; 2) comparability; and 3) outcome. The NOS assigns a maximum score of 4, 2 and 3 for selection, comparability and outcome respectively. High-quality trials scored $\geq 7$, and moderate-quality trials scored $\geq 5$ (maximum possible score equal to 9 ).

\section{Statistical analysis}

The statistical analysis was performed independently by two authors according to recommendations from the PRISMA statement and the Cochrane handbook from the Cochrane Collaboration. Pooled relative risk (RR) with $95 \%$ confidence intervals (95\% CIs) were calculated for each principal dichotomous variable outcome using either a fixed effects model or a random effects model. Values $<1$ did not favor the sarcopenia group and values $>1$ favored the sarcopenia group for overall survival and disease-free survival rate (it should have been the opposite for the parameters such as recurrence and complications rate). We analyzed heterogeneity among the studies using Cochrane's Q test and by calculating $I^{2}$, with $P<0.05$ used to denote statistical significance and with $I^{2}$ calculated to measure the proportion of total variation in the estimates of treatment effect due to heterogeneity beyond chance. No subgroup analysis could be conducted in our meta-analysis because the data extracted from the included studies were not disaggregated by groups. All the statistical analyses were performed using RevMan software, version 5.3, provided by Cochrane Collaboration.

\section{CONCLUSION}

In conclusion, sarcopenia seemed to have a negative effect on OS in patients with primary hepatic malignancies in the early phase post-treatment, but further research is needed to investigate the prognostic impact on OS over the longer term. Also, we concluded that sarcopenia could significantly increase the incidence rates of post-treatment recurrence and overall complications in patients with primary hepatic malignancies. However, due to a lack of the subgroup analysis, sufficient RCTs and prospective cohort studies, the prognostic impact of sarcopenia remains contentious; therefore, future investigations are needed to evaluate the prognostic impact of sarcopenia in primary hepatic malignancies.

\section{Abbreviations}

COPD, chronic obstructive pulmonary disease; DFS, disease-free survival; DM, diabetes mellitus; HCC, Hepatocellular Carcinoma; ICC, intrahepatic cholangio-carcinoma; IMAC, Intramuscular adipose tissue content; L3 SMI, L3 skeletal muscle index; LT, liver 
transplantation; MC, major complication; NOS, NewcastleOttawa Scale; NR, no report; OC, overall complication; OS, overall survival; PRISMA, Preferred Reporting Items for Systematic Reviews and Meta-Analysis; RFA, radiofrequency ablation; VFA, visceral fat area.

\section{Author contributions}

ZGQ participated in design, data collection, studies selection, data analysis/interpretation, and statistics and wrote the first draft. MSF and LRF performed research and wrote the first draft. MSF and YJW collected and analyzed the data. All authors contributed to the design and interpretation of the study and to further drafts. ZLS is the guarantor.

\section{ACKNOWLEDGMENTS}

The authors thank Dr Jvli Lin (department of gastric surgery, Xiehe Hospital of Fujian Medical University) for his valuable suggestion.

\section{CONFLICTS OF INTEREST}

The authors declare no conflicts of interest.

\section{FUNDING}

This study was supported by a grant from program for science \& Technology Innovation Talents in universities of Henan Province (NO.14HASTIT030)

\section{REFERENCES}

1. Rosenberg IH. Sarcopenia: origins and clinical relevance. Clin Geriatr Med. 2011; 27:337-9. https://doi.org/10.1016/j. cger.2011.03.003.

2. Carneiro IP, Mazurak VC, Prado CM. Clinical Implications of Sarcopenic Obesity in Cancer. Curr Oncol Rep. 2016; 18:62. https://doi.org/10.1007/s11912-016-0546-5.

3. Rier HN, Jager A, Sleijfer S, Maier AB, Levin MD. The Prevalence and Prognostic Value of Low Muscle Mass in Cancer Patients: A Review of the Literature. Oncologist. 2016. https://doi.org/10.1634/theoncologist.2016-0066.

4. Harimoto N, Shirabe K, Yamashita YI, Ikegami T, Yoshizumi T, Soejima Y, Ikeda T, Maehara Y, Nishie A, Yamanaka T. Sarcopenia as a predictor of prognosis in patients following hepatectomy for hepatocellular carcinoma. Br J Surg. 2013; 100:1523-30. https://doi. org/10.1002/bjs.9258.

5. Wysham NG, Nipp RD, LeBlanc TW, Wolf SP, Ekstrom MP, Currow DC. A practical measurement of thoracic sarcopenia: correlation with clinical parameters and outcomes in advanced lung cancer. ERJ Open Res. 2016; 2. https://doi.org/10.1183/23120541.00085-2015.
6. Hirasawa Y, Nakashima J, Yunaiyama D, Sugihara T, Gondo T, Nakagami Y, Horiguchi Y, Ohno Y, Namiki K, Ohori M, Tokuuye K, Tachibana M. Sarcopenia as a Novel Preoperative Prognostic Predictor for Survival in Patients with Bladder Cancer Undergoing Radical Cystectomy. Ann Surg Oncol. 2016. https://doi.org/10.1245/ s10434-016-5606-4.

7. Adams SC, Segal RJ, McKenzie DC, Vallerand JR, Morielli AR, Mackey JR, Gelmon K, Friedenreich CM, Reid RD, Courneya KS. Impact of resistance and aerobic exercise on sarcopenia and dynapenia in breast cancer patients receiving adjuvant chemotherapy: a multicenter randomized controlled trial. Breast Cancer Res Treat. 2016; 158:497507. https://doi.org/10.1007/s10549-016-3900-2.

8. Grotenhuis BA, Shapiro J, van Adrichem S, de Vries M, Koek M, Wijnhoven BP, van Lanschot JJ. Sarcopenia/ Muscle Mass is not a Prognostic Factor for Short- and Long-Term Outcome After Esophagectomy for Cancer. World J Surg. 2016; 40:2698-704. https://doi.org/10.1007/ s00268-016-3603-1.

9. Lou N, Chi CH, Chen XD, Zhou CJ, Wang SL, Zhuang CL, Shen X. Sarcopenia in overweight and obese patients is a predictive factor for postoperative complication in gastric cancer: A prospective study. Eur J Surg Oncol. 2016. https:// doi.org/10.1016/j.ejso.2016.09.006.

10. Choi Y, Oh DY, Kim TY, Lee KH, Han SW, Im SA, Kim TY, Bang YJ. Skeletal Muscle Depletion Predicts the Prognosis of Patients with Advanced Pancreatic Cancer Undergoing Palliative Chemotherapy, Independent of Body Mass Index. PLoS One. 2015; 10:e0139749. https://doi. org/10.1371/journal.pone.0139749.

11. Chindapasirt J. Sarcopenia in Cancer Patients. Asian Pac J Cancer Prev. 2015; 16:8075-7.

12. Kamachi S, Mizuta T, Otsuka T, Nakashita S, Ide Y, Miyoshi A, Kitahara K, Eguchi Y, Ozaki I, Anzai K. Sarcopenia is a risk factor for the recurrence of hepatocellular carcinoma after curative treatment. Hepatol Res. 2016; 46:201-8. https://doi.org/10.1111/hepr.12562.

13. Iritani S, Imai K, Takai K, Hanai T, Ideta T, Miyazaki T, Suetsugu A, Shiraki M, Shimizu M, Moriwaki H. Skeletal muscle depletion is an independent prognostic factor for hepatocellular carcinoma. J Gastroenterol. 2015; 50:32332. https://doi.org/10.1007/s00535-014-0964-9.

14. Nault JC, Pigneur F, Nelson AC, Costentin C, Tselikas L, Katsahian S, Diao G, Laurent A, Mallat A, Duvoux C, Luciani A, Decaens T. Visceral fat area predicts survival in patients with advanced hepatocellular carcinoma treated with tyrosine kinase inhibitors. Dig Liver Dis. 2015; 47:869-76. https://doi.org/10.1016/j.dld.2015.07.001.

15. Levolger S, van Vugt JL, de Bruin RW, Ijzermans JN. Systematic review of sarcopenia in patients operated on for gastrointestinal and hepatopancreatobiliary malignancies. Br J Surg. 2015; 102:1448-58. https://doi.org/10.1002/ bjs. 9893 . 
16. Gibson DJ, Burden ST, Strauss BJ, Todd C, Lal S. The role of computed tomography in evaluating body composition and the influence of reduced muscle mass on clinical outcome in abdominal malignancy: a systematic review. Eur J Clin Nutr. 2015; 69:1079-86. https://doi.org/10.1038/ ejen.2015.32.

17. Shachar SS, Williams GR, Muss HB, Nishijima TF. Prognostic value of sarcopenia in adults with solid tumours: A meta-analysis and systematic review. Eur J Cancer. 2016; 57:58-67. https://doi.org/10.1016/j.ejca.2015.12.030.

18. Wells G, Shea B, O'Connell D, Peterson J, Welch V. The Newcastle-Ottawa Scale (NOS) for assessing the quality of nonrandomized studies in meta-analysis. Available: www.ohri.ca/programs/clinical_epidemiology/oxford.asp. Accessed 25 November 2012.

19. Levolger S, van Vledder MG, Muslem R, Koek M, Niessen WJ, de Man RA, de Bruin RW, Ijzermans JN. Sarcopenia impairs survival in patients with potentially curable hepatocellular carcinoma. J Surg Oncol. 2015; 112:208-13. https://doi.org/10.1002/jso.23976.

20. Meza-Junco J, Montano-Loza AJ, Baracos VE, Prado CM, Bain VG, Beaumont C, Esfandiari N, Lieffers JR, Sawyer MB. Sarcopenia as a prognostic index of nutritional status in concurrent cirrhosis and hepatocellular carcinoma. J Clin Gastroenterol. 2013; 47:861-70. https://doi.org/10.1097/ MCG.0b013e318293a825.

21. Valero V 3rd, Amini N, Spolverato G, Weiss MJ, Hirose K, Dagher NN, Wolfgang CL, Cameron AA, Philosophe B, Kamel IR, Pawlik TM. Sarcopenia adversely impacts postoperative complications following resection or transplantation in patients with primary liver tumors. J Gastrointest Surg. 2015; 19:272-81. https://doi.org/10.1007/ s11605-014-2680-4.

22. Voron T, Tselikas L, Pietrasz D, Pigneur F, Laurent A, Compagnon P, Salloum C, Luciani A, Azoulay D. Sarcopenia Impacts on Short- and Long-term Results of Hepatectomy for Hepatocellular Carcinoma. Ann Surg. 2015; 261:1173-83. https://doi.org/10.1097/ sla.0000000000000743.

23. Yabusaki N, Fujii T, Yamada S, Suzuki K, Sugimoto H, Kanda M, Nakayama G, Koike M, Fujiwara M, Kodera Y. Adverse impact of low skeletal muscle index on the prognosis of hepatocellular carcinoma after hepatic resection. Int J Surg. 2016; 30:136-42. https://doi. org/10.1016/j.ijsu.2016.04.049.

24. Takagi K, Yagi T, Yoshida R, Shinoura S, Umeda Y, Nobuoka D, Kuise T, Watanabe N, Fujiwara T. Sarcopenia and American Society of Anesthesiologists Physical Status in the Assessment of Outcomes of Hepatocellular Carcinoma Patients Undergoing Hepatectomy. Acta Med Okayama. 2016; 70:363-70.

25. Harimoto N, Yoshizumi T, Shimokawa M, Sakata K, Kimura K, Itoh S, Ikegami T, Ikeda T, Shirabe K, Maehara Y. Sarcopenia is a poor prognostic factor following hepatic resection in patients 70 years of age and older with hepatocellular carcinoma. Hepatol Res. 2016. https://oi. org/10.1111/hepr.12674.

26. Fujiwara N, Nakagawa H, Kudo Y, Tateishi R, Taguri M, Watadani T, Nakagomi R, Kondo M, Nakatsuka T, Minami T, Sato M, Uchino K, Enooku K, et al. Sarcopenia, intramuscular fat deposition, and visceral adiposity independently predict the outcomes of hepatocellular carcinoma. J Hepatol. 2015; 63:131-40. https://doi. org/10.1016/j.jhep.2015.02.031.

27. Begini P, Gigante E, Antonelli G, Carbonetti F, Iannicelli E, Anania G, Imperatrice B, Pellicelli AM, Fave GD, Marignani M. Sarcopenia predicts reduced survival in patients with hepatocellular carcinoma at first diagnosis. Ann Hepatol. 2017; 16:107-14. https://doi. org/10.5604/16652681.1226821.

28. Hiraoka A, Hirooka M, Koizumi Y, Izumoto H, Ueki H, Kaneto M, Kitahata S, Aibiki T, Tomida H, Miyamoto Y, Yamago H, Suga Y, Iwasaki R, et al. Muscle volume loss as a prognostic marker in hepatocellular carcinoma patients treated with sorafenib. Hepatol Res. 2016. https://doi. org/10.1111/hepr.12780.

29. Kitamura I, Koda M, Otsuka R, Ando F, Shimokata H. Six-year longitudinal changes in body composition of middle-aged and elderly Japanese: Age and sex differences in appendicular skeletal muscle mass. Geriatrics \& Gerontology International. 2014; 14:354-61. https://doi. org/10.1111/ggi.12109.

30. Goodpaster BH, Park SW, Harris TB, Kritchevsky SB, Nevitt M, Schwartz AV, Simonsick EM, Tylavsky FA, Visser M, Newman AB. The loss of skeletal muscle strength, mass, and quality in older adults: the health, aging and body composition study. J Gerontol A Biol Sci Med Sci. 2006; 61:1059-64.

31. Heymsfield SB. Development of imaging methods to assess adiposity and metabolism. Int J Obes (Lond). 2008; 32:S7682. https://doi.org/10.1038/ijo.2008.242.

32. Peng PD, van Vledder MG, Tsai S, de Jong MC, Makary M, Ng J, Edil BH, Wolfgang CL, Schulick RD, Choti MA, Kamel I, Pawlik TM. Sarcopenia negatively impacts shortterm outcomes in patients undergoing hepatic resection for colorectal liver metastasis. HPB (Oxford). 2011; 13:439-46. https://doi.org/10.1111/j.1477-2574.2011.00301.x.

33. Montano-Loza AJ, Meza-Junco J, Baracos VE, Prado CM, Ma M, Meeberg G, Beaumont C, Tandon P, Esfandiari N, Sawyer MB, Kneteman N. Severe muscle depletion predicts postoperative length of stay but is not associated with survival after liver transplantation. Liver Transpl. 2014; 20:640-8. https://doi.org/10.1002/lt.23863.

34. Hamaguchi Y, Kaido T, Okumura S, Ito T, Fujimoto Y, Ogawa K, Mori A, Hammad A, Hatano E, Uemoto S. Preoperative intramuscular adipose tissue content is a novel prognostic predictor after hepatectomy for hepatocellular carcinoma. J Hepatobiliary Pancreat Sci. 2015; 22:475-85. https://doi.org/10.1002/jhbp.236. 